\title{
Decolonising the Teaching of Mathematics in Rural Learning Ecologies by Using Indigenous Games
}

\section{Tshele Moloi \\ ORCID iD: https://orcid.org/0000-0002-3533-2852}

\section{Abstract}

The paper aims at decolonising the teaching and learning of mathematics, such that mathematics is accessible to all learners in rural ecologies. Thus, the paper uses diketo (coordination game), as an example of indigenous games to teach patterns such as linear functions in mathematics. The paper is guided by the theory of community cultural wealth. The theory views community members as experts in rural learning ecologies. The marginalised knowledge they possess empowers them to find their own solutions to local issues. The knowledge that learners possess from the rural learning ecologies is not used in the teaching and learning of mathematics. The researcher maintains that there are no deficiencies in the marginalised knowledge of the excluded people. As a result, the researcher tapped into the marginalised knowledge of subaltern communities to teach linear functions, using participatory action research (PAR) in generating data; hence, the involvement of community members (parents, traditional leaders), education experts (teachers, mathematics subject advisors, lecturers from institution of higher learning) and learners themselves. All the discussions by participants were captured by using tape-recorder and video camera. The generated data were analysed using Van Dijk's critical discourse analysis (CDA). CDA enabled the study to acquire deeper meanings of the text. Again, CDA assists in identifying instances of 'discursive injustices' in text and talk, and signifies a form of resistance to unethical and unjust social power relations.

Keywords: decolonisation, indigenous games (diketo or coordination game), linear functions 


\section{Tshele Moloi}

\section{Introduction and Background}

The aim of this paper is to decolonise the teaching and learning of mathematics so that learners and teachers can have access to hidden knowledge of learning and teaching mathematics. This is argued against the backdrop of colonisation processes of dismemberment and alienation of indigenous knowledge in teaching and learning of mathematical content (Ngugi wa Thiong'o 2009). The question that the paper addresses is the epistemological issue on how mathematical content knowledge is generated within the context of learners in rural ecologies, as well as bringing back the indigenous knowledge of teaching and learning mathematical content to the centre. In this paper, indigenous games such as diketo (a coordination game) will be the focal point in generating mathematical content.

Furthermore, Ndlovu-Gatsheni (2015) views this notion as coloniality of knowledge, useful for enabling decolonial thinkers to understand how endogenous and indigenous knowledges have been relegated to the periphery of 'superior' knowledge, where they exist as folklore and superstitions. In essence, this shows that the Global North perceives Global South cultural activities irrelevant in enhancing mathematical understanding. Largely such indigenous resources (diketo game) are regarded as epistemic dependence (Higgins 2014; Raju 2017) in the learning of mathematical content. Raju (2017) adds that the teaching and learning of mathematics was globalised by colonialism. Hence, there are two ways of teaching mathematics, that is, formal mathematics, used to teach mathematics at schools and universities today. In most cases, this kind of mathematics teaching and learning excludes the epistemologies of the indigenous communities and learners in the rural contexts. The other way is termed 'inferior' way of teaching, that is contextualising of mathematics. This is the approach which the decolonial thinkers argue strongly that it has to be at the centre, where everyone learns mathematics from his/her own perspective. Thus, in this article, it is maintained that learners can learn mathematical content easily when using their indigenous context of playing.

Subsequently, Aikenhead and Elliott (2010), Ndlovu-Gatsheni (2013) and Raju (2017) agree that decolonisation is pushing for an epistemological paradigm shift from using European-American knowledge systems to the use of indigenous knowledge systems. They further argue that decolonising the teaching and learning of mathematical content occurs by recognising indigenous knowledge as being foundational to understanding the physical world of the learners in rural context. The social backgrounds of rural learners 
part of their physical world when learning. Therefore, it is key that the indigenous games they play on a daily basis are infused in the learning of abstract mathematical content. On the other hand, Mosimege (2000) cautions indigenous games need not be perceived in narrow way of enjoyment and play, but as a useful resource for learning mathematical content. In the South African education system, learners do not perform well in mathematics locally, regionally and internationally (Reddy, Isdale, Juan, Visser, Winnaar \& Arends 2016). The teaching and learning of mathematical concepts are divorced from the learners' physical world. Raju (2017) demonstrates that even to understand a simple calculations such as $1+1=2$, most people in the world need the opinion of western-approved experts, and all others (Aikenhead 2006, referred to 'others' as indigenous communities and leaders) are actively distrusted, on account of their 'barbaric' epistemologies. In pushing the decolonisation agenda, the teaching and learning of mathematical content, need to tap into the wealth of knowledges that indigenous communities possess (Martinez 2011; Yosso 2005; Yosso 2002). In furtherance of a decolonisation agenda, the DBE (2011) and Dowling (1998) claim that mathematics is humanistic subject, a feature of all human cultures. Therefore, learners from a rural learning environment who always play diketo can easily comprehend abstract mathematical content. This article concurs with Mertens (2010) that the teaching of mathematical content using diketo is an attempt to decolonise mathematics. Also, to situate indigenous communities and learners consciously in rural learning ecologies as a response to the inequities of a mathematics society with the goal to enhance social justice.

Furthermore, Dowling (1998), and Aikenhead and Elliott (2010) point out that teaching of school mathematics is conventionally Eurocentric or westernised mathematics. This echoes that the Eurocentric understanding of mathematics is exclusively a European product. This phenomenon of teaching caused learners and teachers to teach and learn mathematical content in an abstract way. Hence, the teaching of mathematical content is done in a drilling way, where learners only consume the procedural way of doing mathematics, without conceptual understanding. In addition, Aikenhead (2006) and Romm (2015) contend that the agenda to decolonise school mathematics calls for Indigenous communities and leaders to negotiate appropriate modifications to the provincial mathematics curricula in order to maintain the integrity of indigenous ontologies, epistemologies, axiologies and political realities, which resonate within transformative paradigm. As Mertens (2010) explicates, 


\section{Tshele Moloi}

transformative paradigm is the framework for mathematics decolonial thinkers to prioritise social justice in the teaching and learning of mathematics and the furtherance of human rights. As Raju (2017) puts it, transformative thinking will assist in stopping negative comments on the decolonisation of mathematics. Raju (2017, cited in Brodie 2006) suggests that 'to change the psyche of the Black students (and women), implicitly is to make them think more like the 'dead white men', who created the mathematics subject, and thus turn them into good mathematicians!' This line of thinking deprives black learners of being creative, and defeat the human rights project of recognising potentiality to all learners, irrespective of race, gender, ethnicity and culture. This assertion of Brodie resonates within coloniality of power (NdlovuGatsheni 2015). Again, Raju (2017) maintains that this was the classic colonial line, namely to use colonial education to produce White minds in Black or Brown skins, 'enslaved minds who would hence help run colonial empires'. For instance, Higgins (2014) and Ndlovu-Gatsheni (2015) illuminate coloniality of power as 'constructed, constituted, and configured into a racially hierarchized, Euro-American-centric, Christian-centric, patriarchal, sexist, capitalist, hetero-normative, hegemonic, asymmetrical, modern, colonial and imperial power structure'. This suggests that the world is divided into 'Zones of Being'; that is, those that hold superior mathematical knowledge, located in the global North, and the world of slaves, in the global South, and victims of imperialism, colonialism and apartheid, referred to as the 'Zone of Non-Being'.

As a result, the paper argues the decolonisation of mathematics is possible by exploring the physical world of the child. Hence, diketo is used to unearth rich mathematical content embedded in them. This supports Raju's (2017) declaration that the simple way to decolonise the teaching and learning of mathematics is to have the courage to stand up to false Western history and bad Western philosophy, and focus on the practical value of mathematics. Furthermore, the Department of Basic Education (DBE 2011) and Barker (2012), in persuading the decolonisation agenda, perceive that mathematics is a human activity, which is practised by all cultures, irrespective of race or gender. It is then imperative that the teacher in the mathematics classroom draws on learners' daily life events; that is, engaging in various indigenous games to understand mathematical processes and learning the mathematical content.

Thus, for this reason, Ambrose et al. (2010) argue that this endows/ provides authentic, real-world activity and assigns hands-on activity that 
allows learners to see the relevance and value of otherwise abstract mathematical concepts vividly and concretely, with class activities that allow learners to create a new understanding for themselves. The teacher coaches, scaffolds (Averill et al. 2009) and suggests alternative solutions, whilst at the same time giving the learners room to experiment, discover, ask questions and try things that seemingly do not work.

In the next discussion, an effort will be made to demonstrate how teachers fall into trap of teaching mathematics in a Eurocentric way, as well as suggest how they can be assisted to push the agenda of decolonisation.

\section{Literature Review}

\section{Self-discovery of Problem-solving Skills Formulae and Processes}

Averill et al. (2009) contend that successful teaching of mathematical content creates learning environments conducive to learners, and allows them to invent mathematical definitions and formulae (such as linear functions) on their own. In addition, teachers acknowledge and validate ways of interacting, learning and knowing, and the authors highlight the importance of collaboration among teachers, parents and other community members and leaders. A learning environment that uses indigenous games is central to learning the subject matter, to the extent that teachers teach to demonstrate how teaching mathematical content can incorporate indigenous games, such as diketo. They may enhance feelings of stimulation through activities that develop mathematical ideas; thinking and discovery of mathematical content conjectures, while drawing upon rich resources that learners bring with them to the classroom (Haylock 2010; Sheng \& Basaruddi 2014; Yosso 2002; Yosso 2005).

The use of indigenous games in the teaching of mathematical content creates a learning environment conducive to learners to explore their abilities. The class interaction helps learners to learn many things among themselves without relying on the teacher. In most cases, the teacher is there to clarify misconceptions and validate their findings (Chinn 2012; Muijis \& Reynolds 2011; Van de Walle, Karp \& Bay-Williams 2010). Generally, they learn mathematical content through exploration and finally make their findings and draw mathematical conclusions. Ultimately, learners draw valid conclusions through their observations. The remarkable part of using mathematical content 


\section{Tshele Moloi}

to teach and learn problem skills is that the learners are not provided with formulae by the teacher, but they make the discovery on their own through interaction in small groups.

\section{Lesson Planning in Using Diketo}

According to Averill et al. (2009, in Calman \& Sinclair 2001) and Glynn (1998), reflecting on a Maori worldview of the roles of learners and teachers, lesson planning is intertwined and interchangeable. Since the roles of learners and teachers are interlinked, the contributions made by learners in the planning will help the teacher to design activities that will stimulate learners' interest in mathematics problem solving. As shown by Van de Walle et al. (2010), such collaborative planning draws on rural learners' diverse background experiences and dispositions (The Australian Association of Mathematics Teachers 2006). The pedagogies of Maori learning of mathematics problem solving is through participation, song, storytelling, metaphor, repetition and observation, including routines and patterns of behaviour. The collaborative lesson planning (Averill et al. 2009; Van de Walle et al. 2010), including indigenous parents, learners and teachers, helps to bring together the richness of the marginalised knowledge. The metaphor that describes collaboration in lesson planning is the interaction shown in the playing of diketo as example of indigenous games, where participants work together with passion and focus to create a vibrant lesson presentation and activities.

For example, some resource materials can be prepared for learners to teach mathematical content using the muyato game. This Zambian game of stone throwing is played mostly by girls. It involves digging a hole into which small stones, seeds or round objects are thrown (Mukela 2006). The preparation of the resources can save time on tasks in the learning of mathematical content, as the resources are within the reach of everyone in the indigenous community.

\section{Class Activity in Teaching Mathematical Content}

When learners form part of the planning team, the resources and materials that are prepared by learners and teachers can help the teacher to design activities that stimulate learners' mathematical thinking. The teacher can include the learners' styles in the learning of mathematical content and help learners to 
make connections between prior background knowledge and the new mathematical content to be presented (Haylock 2010). According to Chinn (2012), the involvement of learners in planning and full engagement in the learning of mathematical content has a ripple effect.

Learners are playing but learning at the same time (PramlingSamuelsson 2008). In such cases, interaction amongst learners happens spontaneously. It alleviates mathematics anxiety among learners, as any mismatch between styles of learners and teaching is minimised. Further, Chinn (in Skemp 1971) recommends that over-reliance on rote learning as a dominant culture in teaching mathematical content be avoided, because learners learn mathematical content and concepts with no understanding and merely memorise the content, which in the long run results in anxiety. Ngugi wa Thiong'o (2009) illuminates that this approach of teaching mathematical content advances the 'dismemberment' agenda of the coloniality of knowledge, reiterated as 'Get a few of the natives, empty their hard disk of previous memory, and download into them a software of European memory'. This suggests that indigenous communities have a wealth of knowledge with regard to the teaching and learning of mathematics. However, the Eurocentric and Westernise approach relegates it to the margins of 'superior' knowledge of the Euro-American philosophy. This confirms what Ndlovu-Gatsheni (2017) echoes, namely that Africa and South African people are saddled with irrelevant mathematical knowledge that continues to disempower, rather than empower indigenous communities. Ndlovu-Gatsheni emphasises that indigenous communities and leaders must seriously fight the mathematical knowledge that serves the present asymmetrical global power structure.

\section{The Lens of the Article}

The study is grounded in the theory of community cultural wealth, focusing on the wealth of knowledge that marginalised groups possess. Such knowledge is key to the teaching and learning of mathematical content. In addition, theoretical framework posits that teaching and learning of mathematical content are created by marginalised groups from their everyday lives' experiences, rather than being taught in a formal setting. Thus, Higgins (2014) and Raju (2017) contend that formal mathematics creates a slave mentality. It creates a person who blindly relies on Western authority and conflates it with infallible truth. It can be noted that Community Cultural wealth is compatible 


\section{Tshele Moloi}

with decolonisation processes in demanding the recognition of languages, cultures and knowledge of indigenous communities (Ndlovu-Gatsheni 2015) Lynn (2004) and Yosso $(2002 ; 2005)$ argue that community cultural wealth concentrates on and learns from the range of cultural knowledge, skills, abilities and contacts held by subaltern groups that often go unrecognised and misunderstood. In this article, the use of diketo as an example of indigenous games in teaching mathematical content (that is, linear functions) is a way of recognising and acknowledging the cultural practices of indigenous communities. Again, Raju (2017) mentions that elementary mathematics of fractions was already known to black Egyptians 3700 years ago, before the White man in Greece or Rome could invent them.

Van Oers (2010) agrees with Yosso by introducing the culturalhistorical theory of Vygotsky, which views learning as a process of qualitative change of actions that may take place when people take part in cultural activities and receive guidance for refining or appropriating actions. Van Oers argues that within the cultural-historical context, mathematical content can be defined as a cultural activity that arose somewhere in cultural history and went through a rich and significant cultural-historical development, to end up in the multidimensional and highly advanced discipline as we know it today. On the other hand, Leonard (2008) contends that mathematical problem solving, like all other forms of knowledge, is located within a cultural context. Subsequently, counting and numeracy can conceptually be understood as both a knowledge form and a cultural practice that enable learners to manage and organise their world. Employing cultural norms in the mathematics classroom is at the heart of teaching cultural relevance.

Yosso (2005) argues that the theory of community cultural wealth has various forms of capital, such as aspirational, navigational, social, linguistic, familial and resistant. These draw on knowledge of learners from homes and communities being taken into the classroom environment. The researcher supports Yosso's theory of community cultural wealth and Van Oers's cultural-historical theory, in that using diketo to teach mathematical content is a way of bringing the immediate environment and experiences of the child to the classroom. Van Oers (2010) points out children learn mathematical content optimally when their learning is deep-rooted in playful activities.

Thus, it can be argued that the theory of community cultural wealth dispels the notion that epistemicides, which refer to the killing and expropriation of colonised people' knowledge and history); and linguicides, 
which talk about the destruction of colonised people's languages and cultures and replacement with colonial names and foreign cultures (Ndlovu-Gatsheni 2015), are impossible to happen.

\section{Research Methodology}

The research study utilised participatory action research (PAR), which recognises community members as experts and is empowering for communities who are enabled to find their own solutions to local issues (Moana 2010:10). Miranda, Fine, Torre and Cabana (2018) claim that PAR is beyond a methodological approach; it is an ethical posture, an ethical way to build a relationship with the other. PAR focuses on non-traditional researchers, such as indigenous communities that have not been classically trained in research. It is interesting to realise that in PAR they switch roles and become the designers of research.

In the context of this study, the researcher and participants were empowered by using indigenous games to solve problems and identify mathematical concepts embedded in them. The marginalised capital was explored to understand problem solving by using cultural games, particularly indigenous ones. As Yosso (2005) argues, there is a lot of cultural capital in the communities that is not adequately utilised. In addition, Miranda et al. (2018) demonstrate that PAR creates spaces where different kinds of knowledge come together about the social problems and radical possibilities in addressing the identified challenge.

The researcher assembled a team of Grade 10 learners at one school located in the rural area of Qwaqwa. He further included one deputy principal, one head of department (HOD), three Grade 10 Mathematics teachers, two Life Orientation teachers, two district officials from the Department of Basic Education (DBE) - one in the sports section, two Mathematics subject advisors, 10 parents with knowledge of various indigenous games and two members of the royal family who are custodians of cultural games, as well as a lecturer in the School of Mathematics, Science and Technology Education from the University of the Free State (Qwaqwa Campus).

The framework was implemented at one school in the rural area of Qwaqwa, in the Thabo Mofutsanyana Education District. For confidentiality and anonymity, the school and participants were given pseudonyms. In stimulating the debate, the Free Attitude Interview (FAI), Maskene (2011) was 


\section{Tshele Moloi}

followed to ensure that participants were central to the research study and their voices heard, rather than being perceived as objects to be manipulated and regulated in a setting detached from the real world of their lived experiences and practices (McGregor \& Murnane 2010; Stinson 2012).

Thus, PAR provides a new perspective called epistemic justice; that is, a commitment to a radical reimagination of where knowledge and expertise exist. Within the PAR spaces, various people (researchers/ co-researchers/ research participants) actively seek options for 'social change'. Indigenous peoples and scholars from marginalized communities have much to teach researchers about respect for culture and the generation of knowledge for social change (Miranda et al. 2018; Romm 2015)

\section{Plan of Action Executed in Teaching Linear Functions Using Diketo}

The research study demonstrated interdisciplinary notions by including Life Orientation subjects, Mathematics, Sport personnel, traditional leaders, parents and learners. This further demonstrates what Wane (2009) regards as the inclusion of indigenous voices in the main curriculum, signifying that the positivist forms of knowing, educating and doing science and research are challenged (Denzin 2010).

\section{Phase One: Playing Diketo}

In Phase One, the chosen group members played diketo (coordination game) as scheduled for that day. As Sancar-Tokmak (2013) states, this phase follows a juxtaposition model, with teachers and parents, while a group of learners watched another group of children during their free play and noted mathematical key points that could be used in designing a mathematics lesson. Vankúš (2008) states that learners' active involvement during the play of indigenous games is important for better comprehension of mathematical knowledge embedded within the games. This phase is conducted in such a way that the actual play is demonstrated, important observations are noted, and children are encouraged to explore new mathematical ideas and skills (SancarTokmak 2013; Vankúš 2008). At the end of the phase, the teachers arrange activities to teach mathematical concepts or skills noted during play, or concepts identified by the learners, teachers and parents. 


\section{Phase Two: Reflection on the Lesson Learnt from Playing Diketo}

At the end of the game, all members shared their observations and attitudes towards the playing of diketo. This is when teachers noted teachable moments or mathematical concepts, which became apparent during the children's free play or parents' play. Sancar-Tokmak (2013) and Vankus (2008) call this the 'integration model', when contextual issues demonstrated during play of diketo are linked to the mathematical knowledge identified. However, in the research study, the discussion was free for all participants to share observations. As Godino, Batanero and Font (2007) indicate, the discussions touched on various facets, such as sociocultural skills demonstrated by players and epistemological matters on how knowledge is accessed through play. All members in a group were on the same level during the discussion. Denzin (2010) propagates the decolonisation project, which supports the idea that all participants are on an equal level in terms of knowledge, and everyone is free to lead the discussions. This emphasises the importance of social wealth, sharing of which means participants can learn from one another.

During the reflection stage, the discussions are not limited to state of the play or likelihood of winning, but include children's conceptual understanding of intertwining the game structure and game play with the mathematical concepts (Booker 2004).

\section{Phase Three: Presentation of the Lesson}

The teacher prepared the presentation of the lesson in such a way that forms of the contextualisation of mathematics was taken into account. The teacher chose the mathematical content (that is, linear functions) from the ones, which were suggested in Phase Two as the main topic for the day, as that allowed the spontaneous integration of topics mentioned before. The class activities were designed in such a way that learners worked together in finding solutions to the activities assigned to them. Vankus (2008) and Alexander and James (2005) state that creating a conditions for the indigenous games in the classroom, in this study diketo, as the context in presenting the mathematics lesson in class, enhances learners' interest in mathematics. They can relate their understanding of their well-known and well-practiced usual games to mathematical content. In addition, this approach motivates and encourages them to take part in class discussions, and to come up with innovative, creative ideas; hence, resulting in a greater likelihood of success in mathematics. 


\section{Tshele Moloi}

\section{Phase Four: Reflection on the Lesson Presented}

Learners in small groups were given a chance to share what they have learnt in the activities with the whole class. Reflections and feedback on the ontosemiotic approach provides dual dimensions of extensive-intensive facet, wherein several observations are made to reach substantiated conclusions (extensive case) and vice versa (that is, intensive cases). These are key in the construction and application of mathematical knowledge (Godino et al. 2007). These are important mathematical practices, which provide learners with the means to develop mathematical arguments and justifications that lead to robust concepts and thinking (Booker 2004; Alexander \& James 2005). In this study, the teachers and parents played a key role in guiding the process of reflection, and provided input on issues that were confusing to learners, the exciting moments during the session and when learners found ways to take centre stage in the learning and teaching, making excellent contributions. In essence, all parties need to be prepared for the lesson presentations, not only the teacher. This concurs with the claim by Alexander and James (2005) and Booker (2004), that this session of feedback encourages learners to work independently and enhances instructional group teaching. In this way, indigenous games such as diketo induce learners to make sense of their ideas and the interpretations of others. Significant for this research study, the learners were able to conceptualise and internalise the definition of mathematics, that 'it is human activity practised by all cultures' (DoE 2003; DBE 2011; Vilela 2010). It is a social process of sense-making, understanding, rather than a set of rules handed down from an authority on high (Booker 2004; Raju 2017).

\section{Phase Five: Assessment}

It is understood that assessment is conducted throughout the phases as a way of integrating all activity with teaching and assessment (DoE 2003). Booker (2004) regards it as essential that the game (in this instance, diketo) achieves the educational and mathematical outcomes to be assessed for it to be effective. Assessment tasks are performed as a way of reinforcing the understanding of certain mathematical concepts.

Generally, this was the plan of action, which was executed in collaboration with indigenous communities and learners in the rural learning ecology to teach linear functions, using the pupils' understanding and practice of diketo. 


\section{Discussions and Findings}

\section{Decolonising Pedagogies: Self-discovering of Linear Functions, in Formulas and Processes Using diketo}

The teaching modes that mathematics teachers used in this study incorporated the indigenous knowledge learners possess from their social environment with the knowledge they were about to learn pertaining to linear functions. Thus, the teacher used various teaching methods to ensure that the learners were actively involved in the learning of linear functions (Assembly of Alaska Native Educators 2003; Assembly of Alaska Native Educators 2002; Kemp 2006).

The research study used diketo to teach linear functions to ensure that learners were fully engaged. This concurs with what Booker (2004) and Mosimege (2000) maintain, namely that the playing of these indigenous games should not be viewed from the narrow perspective of play, enjoyment and recreation, but rather ensure that the learning of mathematical contents is effective. Learners also showed full participation during the lesson presentations. The use of diketo in teaching derivations of linear functions contextualised the subject matter for learners to access it easily.

\section{Lesson Presentation in Using Diketo}

According to Kemp (2006), Mason (2010), Warren and Miller (2013) and Yosso (2005), the majority of learners enter school with huge knowledge on mathematical processes such as critical thinking, analysis, navigational reasoning, conjecturing, and extrapolation skills. The teacher has to use the teaching methods that will activate these skills to be relevant in understanding problem-solving skills. In this research study, diketo was used for rural learners to understand derivation of linear functions, thus encouraging learners to be actively involved throughout the learning sessions.

In Phase One, the team chose to play diketo (A coordination game) (refer to Picture 1 below). During Phase Two, when the collective reflection took place, one of the group reported their findings of mathematical concepts, skills embedded within diketo. Dikopi, the spokesperson of the group, reported as follows: 
Dikopi: re bona mokoti o rono, le majwe a chitja a tene. Ha o bapala o akgela keto hodimo o nto sutuletsa majwe ka mokoting. Ho seng one, kgetlo la pele o akgela keto hodimo, o ntano ntsha majwe a naene ka mokoting, jwalo-jwalo, ho fihlela o qeta seng one. Ha o qetile o fetela seng two, jwalo jwalo ho latela pattern, ho fihlela o fihla seng tene.

(We see the round hole, ten small round stones and one big round stone (ghoen). In round one, you throw the ghoen into the air. At the same time, you scoop or lift all the stones in the hole; throw it into the air and place the nine round small stones. One follows this pattern until you complete round one and move on to round two, continuing till you reach round ten.)

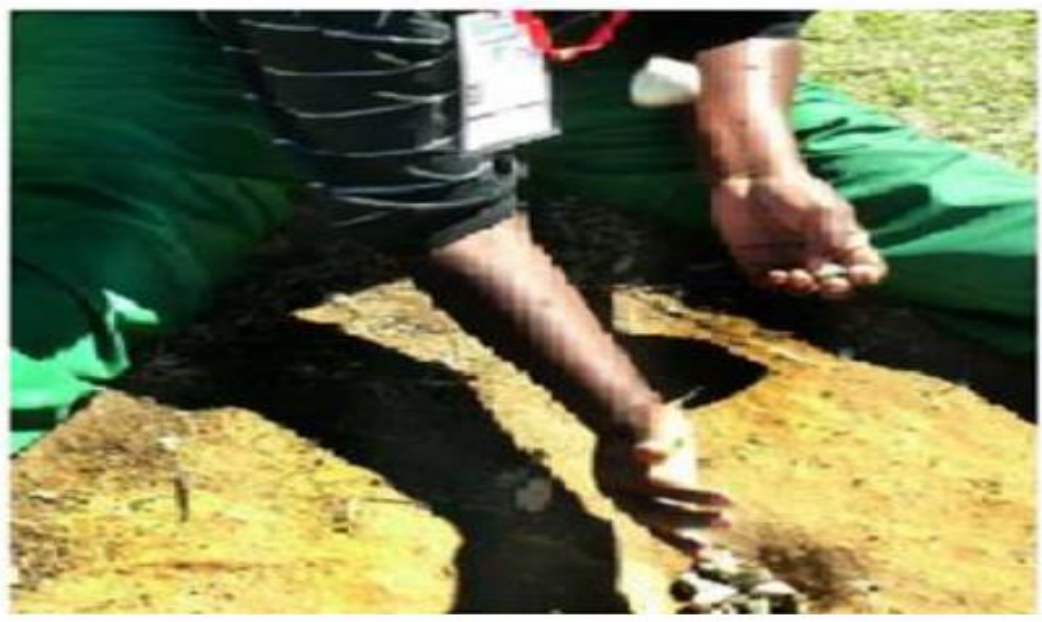

\section{Picture 1: One Team member plays diketo}

Subsequently, the team summarised the concepts and skills in this fashion (see Fig.1 below). The following concepts and skills came out strongly in most of the groups. 


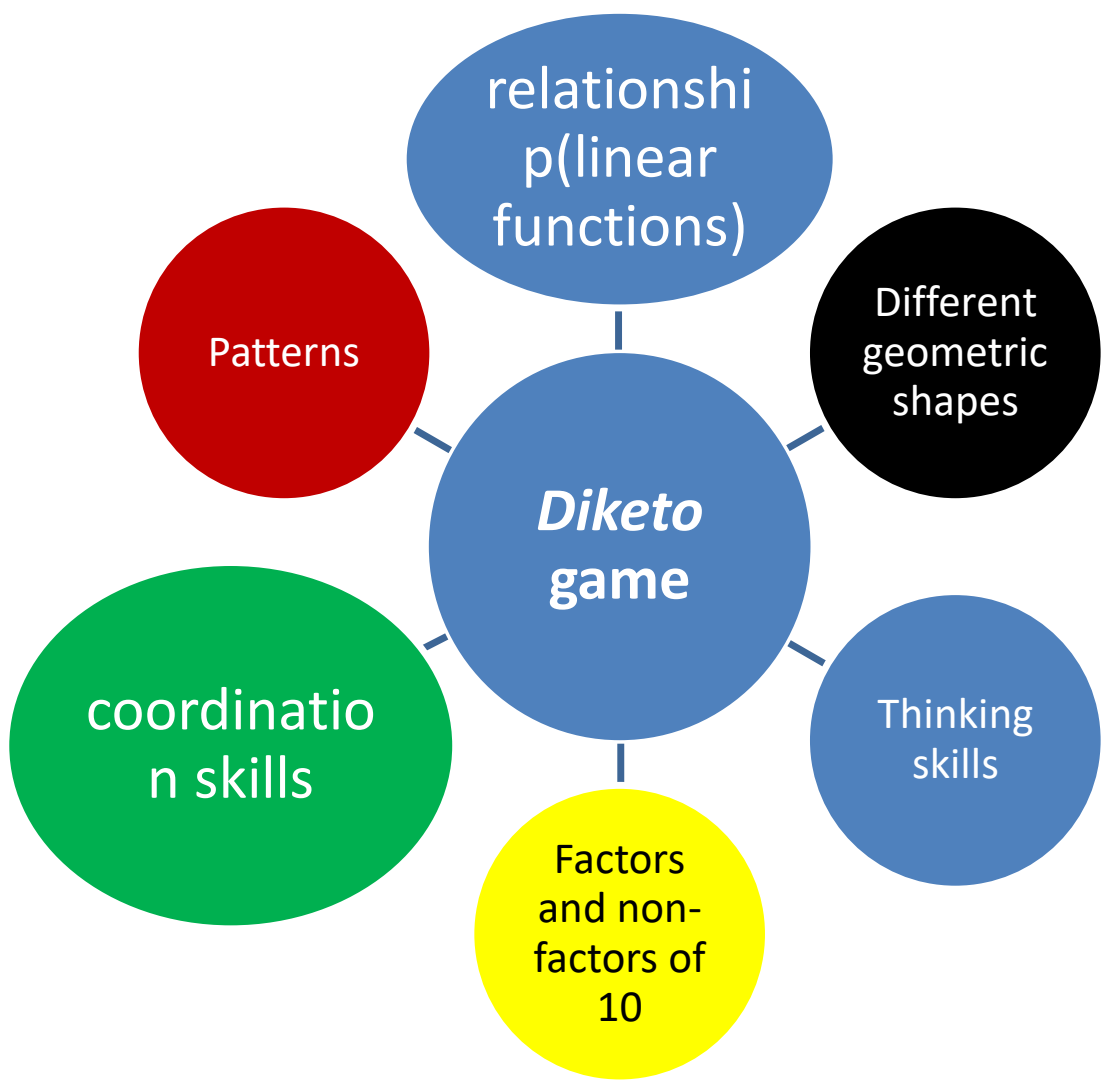

Fig. 1: Some mathematical concepts that emanated from diketo

The teacher, Ms Lejwe, who led the lesson presentation, took the patterns and linear functions (relationship) and the scenario painted by Dikopi's group to design the class activity (Worksheet 1 below). This allowed various groups to be fully involved. The teachers, other experts and parents facilitated discussions in various groups. They gave assistance by empowering learners to discover and reflect on their own. The modes they used in assisting the groups varied from scaffolding, modelling, facilitating, coaching and reflection, and any other suitable modes. The emphasis of their teaching modes was ensuring that learners discovered answers on their own. 


\section{WORKSHEET No. 1}

Instructions:

With the help of the scenario, given by Dikopi's group, develop a strategy that will assist you to respond to the questions below:

(a) In the $2^{\text {nd }}, 12^{\text {th }}$, and $16^{\text {th }}$ throw-ins, how many stones will be pushed into the hole?

(b) In round one (seng one), how many throws of the ghoen (keto) need to be made to complete round one

(c) At which throws, will one scoops 5 stones, 3 stones out of the hole.

(d) If there is two stones in holes, how many throws were done

(e) $\left(1^{\text {st }}\right.$ throw; 10$),\left(2^{\text {nd }}\right.$ throw; 9$) \ldots\left(20^{\text {th }}\right.$ throw; 0$)$. On the set of axes, plot these points.

(f) (i) Suppose, that there are 20 stones to be used, on the $6^{\text {th }}$ throwin, how many stones will be put in the whole?

(ii) In round one (seng one) given that there are 20 stones (diketwana), how many throws need to be done to complete round one successfully.

After 30 minutes, the teacher, Ms Lejwe allowed various groups to report on their findings. The parent, Mma Sebereki, from Group A, give the feedback of their group in this manner:

Mma Sebereki: Kgotsong banabeso. Re leboha sebaka seo re se fuwang ho fana ka dikarabo tsa akthivithi eo re e fuweng. Haeba o hloka tlhakisetso kapa tlatsetso o ka etsa jwalo neng kapa neng. Re ile ra bapala diketo hape hore re arabe ditsopo. Ra fumana hore ka kgetlo la bodedi majwe a kenang ka mokoting ke 9, $12^{\text {th }}$ ke majwe a 4, and $16^{\text {th }}$ ke ketwana tse 2. Potso ya bobedi, hore o qete seng one o lokela ho ba le makgetlo a 19. 
(Good morning colleagues. We want to thank the opportunity given to us to give feedback on our answers. If you need clarifications or you want to comment, feel free to do so at any point, my group members will assist to respond. To answer the questions, we demonstrated by playing diketo again. Through the play of diketo we deduce the following: for the $2^{\text {nd }}$ throw, there are 9 stones to be pushed into the whole, $12^{\text {th }}$ throw there are 4 stones and $16^{\text {th }}$ throw there are 2 stones. The patterns can be followed in that way. To complete round one, there are 19 throws to be made.)

Everybody was so interested in the manner the presentation was done. The other group gave an alternative way of answering the very same question. Dinweng, from Group $\mathrm{C}$, showed their appreciation in the following fashion:

Dinweng: Thank you, Chair, let me thank the previous presenters, that is Group A for the wonderful manner they did their presentation. What we did in our group is, we also demonstrated the play of diketo for few minutes, as we do that we recorded the throws done is this manner. The table below assisted us to put our data in an orderly manner. It enabled us to respond to all the questions.

Dinweng: Like the previous group, we used the table to respond to the questions, for the $2^{\text {nd }}$ throw there are 9 stones placed into the hole; for the $12^{\text {th }}$ throw, there are 4 stones to be placed in a hole, and for the $16^{\text {th }}$ throw there are 2 stones to be placed in a hole. The strategy of drawing the table really assisted us a lot.

The extract, 'We see the round hole, ten small round stones and one big round stone (ghoen)', illustrates that learners were empowered to capacitate others in analysing diketo to demonstrate the existence of mathematical content in the play of diketo. Since learners were empowered to explain, mathematical concepts and skills infused in diketo, that action boosted their self-esteem and confidence. 


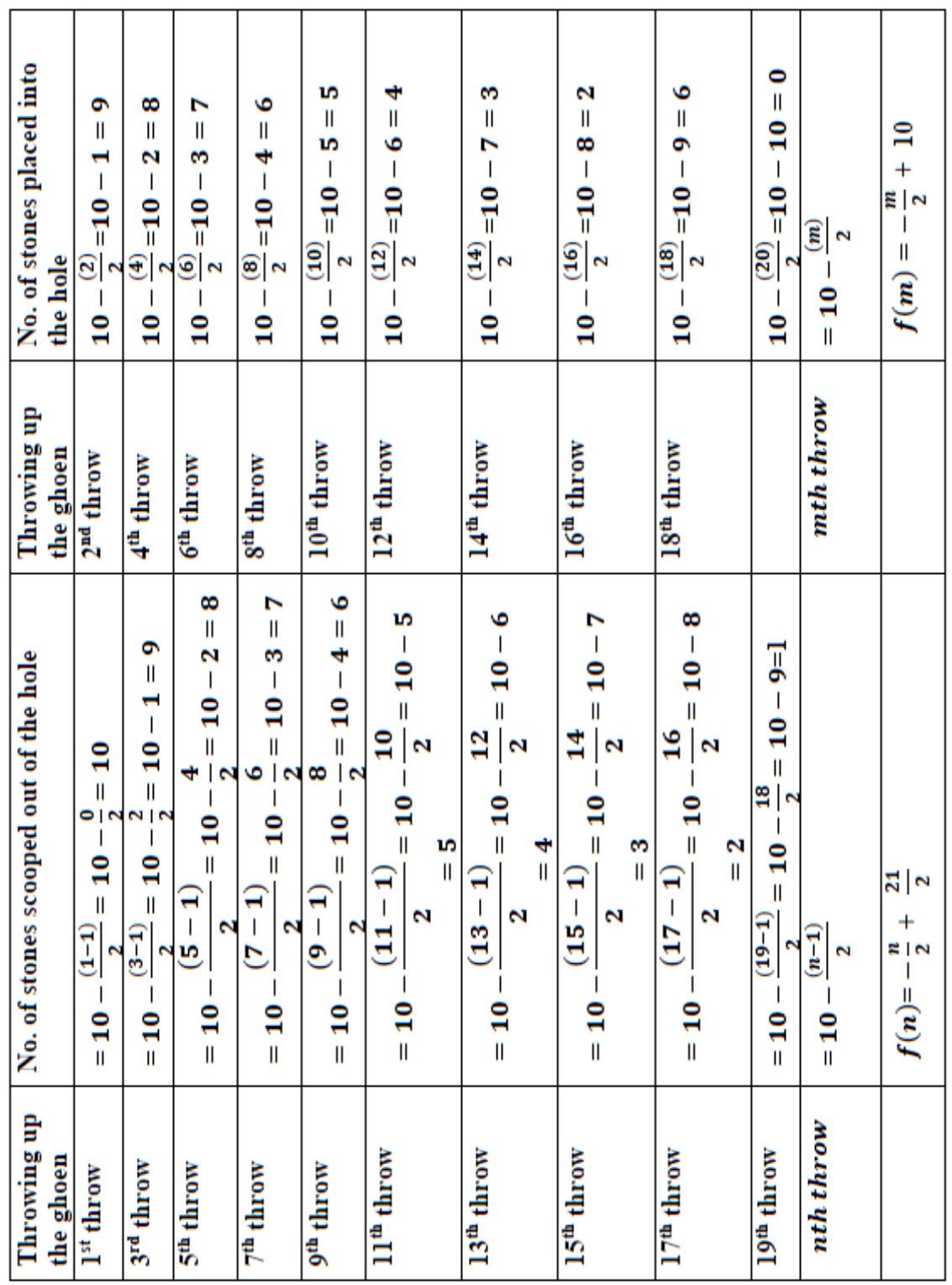


This is amplified by Dinweng's comment' $\ldots \mathbf{1 0}-\frac{(\mathbf{2})}{\mathbf{2}}=\mathbf{1 0}-\mathbf{1}=\mathbf{9}$ ...' as their alternative method used to get the nine stones which were put in the hole for the $2^{\text {nd }}$ throw of the ghoen. This demonstrates that the power of teaching mathematical content and skills is no more limited to the teachers' input. Learners gained power on understanding mathematical content such as linear patterns and functions in simpler ways for learners to come up with various ways of answering the class activity, aided by their possession of navigational capitals.

They further displayed good interpersonal relations among team members, where they honestly shared their inputs with rest of the class. The phrase '... let me thank the previous presenters, that is, group A for the wonderful manner they did their presentation', symbolises that their interpersonal skills were good and that they were at peace with one another. This is in line with what Yosso (2005) refers to as learners' aspirational capital, where they are capable to maintain positive hope for the future. Everyone is given hope that he or she can manage to do well in understanding the derivation of linear functions, irrespective of their social class, age or gender. This is also supported by the transformative paradigm that axiological values are instilled. For effective interactions and networking to happen in understanding mathematical concepts and skills, this is because of the social capitals that learners have. In addition, the richness of linguistic capital allows them to be very clear in explaining the structural and the actual playing of the game. The manner in which they articulate responses to the class activity was marvellous. This approach of teaching is in line with decolonisation agenda, to such an extent that linguicide issues are destructed in the minds of rural learners (Ndlovu-Gatsheni 2015).

The arguments above relate to what the Assembly of Alaska Native Educators (2003) and D'Ambrosio (2009) established. As the research study confirms, they established that the use of curricular and various instructional methods enhances learners' understanding of mathematical concepts and skills. This encourages rural learners to work together, not heavily depending on the teacher. Likewise, the use of cultural practices (such as indigenous games, in particular diketo) known to learners helps to enrich and give meaning to what is taught in mathematics.

Again, learners engage in the experimentation and exploration processes in interacting with diketo to explore mathematical concepts and 


\section{Tshele Moloi}

skills. By carrying out experimentation and exploration processes, learners tend to discover funny things or options (which are referred to as wrong things), while and other processes or options that come right from the onset(Raju 2017). As Yosso (2005) indicates, learners possess aspirational and navigational capitals. This argument is justified by Warren and Miller (2013), who state that the alternative formulas, which might look funny, provoke learners to continue to explore or discover linear functions and formulas until reaching the correct conclusions. These explorations, experimentations and early patterning help learners to understand the derivations of linear function skills.

\section{Conclusion}

In a nutshell, the discussions and narratives portray that a decolonisation agenda can be achieved in the teaching and learning of mathematical concepts. Mathematical content embedded within diketo include patterns, factors and non-factors, geometric shapes and relationships of variables and many more. Teachers, as decolonial thinkers, need to tap into the physical world of learners, in order to stimulate mathematical knowledge. In addition, their teaching approaches should not suppress learners whose home culture often differs from the culture of school mathematics. In most cases, school mathematics is saddled with Euro-American mathematics knowledge systems. Aiken (2017) and Raju (2017) contend that school mathematics overtly and covertly marginalise indigenous communities and rural learners by its ideologies of neo-colonialism, where learners' cultural values are undermined in the learning of mathematics.

\section{References}

Aikenhead, G.S. 2006. Towards Decolonizing the Pan-Canadian Science Framework. Canadian Journal of Science, Mathematics and Technology Education 6,4: 387 - 399. https://doi.org/10.1080/14926150609556712 Aikenhead, G.S. \& D. Elliott 2010. An Emerging Decolonizing Science Education in Canada. Canadian Journal of Science, Mathematics and Technology Education 10,4:321-338.

https://doi.org/10.1080/14926156.2010.524967 
Alexander. J. \& J. James 2005. Mathematics Games: A Waste of Time or a Great Learning Experience? The Adviser Magazine 15 - 19.

Ambrose, S.A., M.W. Bridges, M. DiPietro, M.C. Lovett \& M.L. Norman 2010. How Learning Works: Seven Principles. Research-based Principles for Smart Teaching. U.S, San Francisco: Jossey-Bass.

Assembly of Alaska Native Educators 2002. Guidelines for CulturallyResponsive School Boards. Alaska: Native Knowledge Network.

Assembly of Alaska Native Educators 2003. Guidelines for Cross-Cultural

Orientation Programs. Alaska: Alaska Native Knowledge Network.

Australian Association of Mathematics Teachers 2006. Standards for Excellence in Teaching Mathematics in Australian Schools. Adelaide: Australian Association of mathematics Teachers Inc.

Averill, R., D. Anderson, H. Easton, P. te Maro, D. Smith \& A. Hynds 2009.

Culturally Responsive Teaching of Mathematics: Three Models from Linked Studies. Journal for Research in Mathematics Education 40,2: $157-186$.

Barker, C. 2012. Cultural Studies: Theory and Practice. California US: Sage Publications.

Booker, G. 2005. Thinking Mathematically - Making Sense and Solving Problems. In Proceedings of International Conference. The Mathematics Education into the 21 st Century Project University Technology Malaysia Reform, Revolution and Paradigm Shifts in Mathematics Education, Johor Bahru, Malaysia, 25 November - 1 December 2005.

Booker, G. 2004. Playing to Win: Using Games for Motivation and the Development of Mathematical Thinking. In Proceedings of International Conference. The Mathematics Education into the $21^{\text {st }}$ Century Project: The Future of Mathematics Education, Pod Tezniami, Ciechocinek, Poland. 26 June - 1 July 2004.

Chinn, S. 2012. More Trouble with Mathematics: A Complete Guide to Identifying and Diagnosing Mathematical Difficulties. New York USA: Routledge. https://doi.org/10.4324/9780203117392

D’Ambrosio, U. 2009. Mathematical Modeling: Cognitive, Pedagogical, Historical and Political Dimensions. Mathematical Modelling and Application 1,1: 89 - 98.

Denzin, N.K. 2010. Grounded and Indigenous Theories and the Politics of Pragmatism. Sociological Inquiry 80,2: 296 - 312.

https://doi.org/10.1111/j.1475-682X.2010.00332.X 
Department of Basic Education 2013a. Report on the 2013 National Senior Certificate Diagnostic Report. Pretoria: Department of Basic Education.

Department of Basic Education 2013b. Annual Assessment 2013 Diagnostic Report and 2014 Framework for improvement. Pretoria: DBE.

Department of Basic Education 2013c. Annual Report 2012/13. Pretoria:

Department of Basic Education. R.S.A.

Department of Basic Education 2009. National Examinations and Assessment Report on the National Senor Certificate Examinations Results. Pretoria: Department of Basic Education.

Department of Basic Education 2011. Mathematics: Curriculum and Assessment Policy Statement Grades 10 - 12. Pretoria: Department of Basic Education.

Department of Basic Education 2011. National Protocol for Assessment Grades R-12. Pretoria: Department of Basic Education.

Department of Education 2003. National Curriculum Statement Grades 10 -

12 (General): Mathematics. Pretoria: Department of Education.

Dowling, P. 1998. Sociology of Mathematics: Mathematical Myths/Pedagogic

Texts. (Studies in Mathematics Education Series.) Washington DC: The

Falmer Press.

Ernest P. 1989. Philosophy, Mathematics and Education. International Mathematics Education Science and Technology 204: 555 - 559.

https://doi.org/10.1080/0020739890200409

Ernest, P. 1997. The Epistemological Basis of Qualitative Research in Mathematics Education: A Postmodern Perspective 9: 22 - 39.

https://doi.org/10.2307/749945

Gerdes, P. 2001. Exploring the Game of 'julirde': A Mathematical-educational

Game Played by Fulbe Children in Cameroon: Teaching Children Mathematics. National Council of Teachers of Mathematics 76: 321 - 327. https://doi.org/10.1007/s11858-009-0208-2

Gerdes, P. 2009. Exploration of Technologies, Emerging from African Cultural Practices, in Mathematics (Teacher) Education. ZDM Mathematics Education 42: 11 - 17.

Godino, J.D., C. Batanero \& V. Font 2007. The Onto-semiotic Approach to

Research in Mathematics Education. ZDM-The International

Mathematics Education 39,1-2: 127 - 135.

https://doi.org/10.1007/s11858-006-0004-1

Graven, M. 2003. Learning as Changing Meaning, Practice, Community, Iden- 
tity and Confidence: The Story of Ivan. Learning of Mathematics 23,2: 28 $-36$.

Graven, M. 2005. Teacher Learning as Changing Managing Practice: Community, Identity and Confidence: The Story of Ivan. Learning of Mathematics 23,2: 28 - 36.

Graven, M. \& M. Schafer 2013. Interview with a Mathematics Doodler - Dr

Sizwe Mabizela, Deputy Vice Chancellor, Rhodes University. In Bizony,

M. \& L. Tshabalala (eds.): Grahamstown: Amesa, Learning \& Teaching Mathematics.

Haylock, D. 2010. Mathematics Explained for Primary Teachers. $4^{\text {th }}$ Edition.

California: SAGE Publications.

Higgins, M. 2014. De/colonizing Pedagogy and Pedagogue: Science Education through Participatory and Reflexive Videography. Canadian Journal of Science, Mathematics and Technology Education 14,2: 154 - 171.

https://doi.org/10.1080/14926156.2014.903321

Kemp A.T. 2006. A Case for a Place-based Curriculum. Curriculum and Teaching Dialogue, 8: 125 - 142.

Leornard, J. 2008. Culturally Specific Pedagogy in the Mathematics Classroom: Strategies for Teachers and Students. Routledge Taylor \& Francis Group.

Lybeck, E.R. 2010. The Critical Theory of Lewis Mumford. International Journal of Interdisciplinary Social Sciences 5,1: 91 - 102.

https://doi.org/10.18848/1833-1882/CGP/v05i01/59362

Lynn, M. 2004. Inserting the 'Race' into Critical Pedagogy: An Analysis of Race-based Epistemologies. Educational Philosophy of Theory 36,2: 153 - 164. https://doi.org/10.1111/j.1469-5812.2004.00058.x

Martinez, M.A. 2011. College Choice Experience of Mexican American Students within their Community Context. Journal of Hispanic Higher Education 11,1: 67 - 81. https://doi.org/10.1177/1538192711428992

Maskene, I. 2011. The Free Attitude Interviews in Context. Research for the Future. Unpublished Paper.

Mason, J. 2010. Mathematics Education: Theory, Practice \& Memories over 50 Years. The Learning of Mathematics 30,3: 3 - 9.

McGregor, S.L.T. \& J.A. Murnane 2010. Paradigm, Methodology and Method: Intellectual Integrity in Consumer Scholarship. International Consumer Studies 34,4: 419 - 427.

https://doi.org/10.1111/j.1470-6431.2010.00883.x 
Mertens, D.M. 2010. Transformative Mixed Methods Research. Qualitative Inquiry 16,6: 469 - 474.

https://doi.org/10.1177/1077800410364612

Miranda, L.L., M. Fine, M.E. Torre \& A. Cabana 2018. Participatory Action Research (PAR) with LGBT+ \& GNC Youth in the United States: An Interview with Michelle Fine, Maria Torre and Allison Cabana. Revista de Psicologia, Fortaleza 9,1: 132 - 140.

Moana, E. 2010. Ma Te Whānau Te Huarahi Motuhake: Whānau Participatory Action Research Groups. MAI Review 3.

Mosimege, M.B. 2000. Research Methods in Indigenous Mathematical Knowledge: An Example of a Research Model Based on Indigenous Games. Indilinga - African Journal of Indigenous Knowledge System 1124.

Muijs, D. \& A. Reynolds 2011. Effective Teaching Evidence and Practice. California: SAGE Publishers Ltd.

Mukela, M.R. 2013. The Role of Indigenous Music and Games in the Promotion of Cognitive Development in Zambian Children: Senanga and Shangombo Districts of Western Province. Unpublished Dissertation, University of Zambia: Zambia.

Ndlovu-Gatsheni, S.J. 2012. Fiftieth Anniversary of Decolonisation in Africa: A Moment of Celebration or Critical Reflection? Third World Quarterly 33,1: 71 - 89. https://doi.org/10.1080/01436597.2012.627236

Ndlovu-Gatsheni, S.J. 2015. Decoloniality in Africa: A Continuing Search for a New World Order. ARAS 2236,2: 22 - 50.

Ngugi wa Thiong'o 2009 Re-membering Africa. Nairobi: East African Educational Publishers Ltd.

Odora-Hoppers, C.A. 2000. The Centre - Periphery in Knowledge Production in the Twenty-first century. Compare: A Journal of Comparative and International Education 30,3: 283 - 291.

https://doi.org/10.1080/713657471

Perez-Huber, L. 2009. Challenging Racist Nativist Framing: Acknowledging the Community Cultural Wealth of Undocumented Chicana College Students to Reframe the Immigration Debate. Harvard Educational 79,4: 704 - 730. https://doi.org/10.17763/haer.79.4.r7j1xn011965w186

Raju, C.K. 2017. Black Thoughts Matter: Decolonized Math, Academic Censorship, and the 'Pythagorean' Proposition. Journal of Black Studies 48,3: 256 - 278. https://doi.org/10.1177/0021934716688311 
Reddy, V., K. Isdale, A. Juan, M. Visser, L. Winnaar \& F. Arends 2016. TIMSS 2015: Highlights of Mathematics Achievement of Grade 5 South African Learners. Available at:

http://www.hsrc.ac.za/en/research-outputs/view/8456

Sancar-Tokmak, H. 2013. The Effect of Curriculum-generated Play Instruction on the Mathematics Teaching Efficacies of Early Childhood Education Pre-service Teachers, European Early Childhood Education, Computer Education and Instructional Technology. Mersin, Turkey: Mersin University. https://doi.org/10.1080/1350293X.2013.788315

Sheng, E.L. \& F. Basaruddin 2014. Ways of Improving Students' Performance in Assessments from Instructors and Students' Perspectives. International Journal of Asian Social Sciences 4,2: 301 - 306.

Stinson, D.W. \& E.C. Bullock 2012. Critical Postmodern Theory in Mathematics Education Research: A Praxis of Uncertainty. Educational Studies 80: 41 - 55. https://doi.org/10.1007/s10649-012-9386-X

Tuhiwai, S.L. 2001. Decolonizing Methodologies: Research and indigenous People. Social Policy Journal of New Zealand 17: 214 - 217.

Van de Walle, J.A., K.S. Karp \& J.M. Bay-Williams 2010. Elementary \& Middle School Mathematics: Teaching Developmentally. US: Pearson Education, Inc.

Van Dijk, T.A. 2001. Discourse, Knowledge and Ideology: Reformulating Old Questions and Proposing Some New Solutions. Washington: The Washington Post Company.

Vankúš, P. 2008. Game-based Learning in Teaching of Mathematics at Lower Secondary School. Acta Didactica Universitatis Comenianae Mathematics 8 .

Van Oers, B. 2010. Emergent Mathematical Thinking in the Context of Play. Education Studies in Mathematics 74: 23 - 37.

https://doi.org/10.1007/s10649-009-9225-X

Vilela, D.S. 2010. Discussing a Philosophical Background for the Ethnomathematical Program. Educational Studies in Mathematics 75: 345 358. https://doi.org/10.1007/s10649-010-9261-6

Vorderman, C. 1996. How Mathematics Works. London: Dorling Kindersley Limited.

Wane, N.J. 2009. Indigenous Education and Cultural Resistance: A Decolonizing Project. The Ontario Institute for Studies in Education of the University of Toronto. Curriculum Inquiry 39:1. 
https://doi.org/10.1111/j.1467-873X.2008.01443.x

Warren, E. \& J. Miller 2013. Young Australian Indigenous Students' Effective

Engagement in Mathematics: The Role of Language Patterns, and

Structure. Mathematics Education Research Journal 25,1: 151 - 171. https://doi.org/10.1007/s13394-013-0068-5

Yosso, T.J. 2002. 'Toward a critical race curriculum'. Equity \& Excellence in Education 35,2: 93 - 107. https://doi.org/10.1080/713845283

Yosso, T.J. 2005. Whose Culture has Capital? A Capital Race Theory Discussion of Community Cultural Wealth. Race, Ethnicity and Education 8,1: 69 - 91. https://doi.org/10.1080/1361332052000341006

Moloi Tshele Mathematics Education Faculty of Education Potchefstroom Campus North West University tshelej@gmail.com 37591363@g.nwu.ac.za 37591363@nwu.ac.za 